\title{
Adaptation to risks related to ecotourism: development at Boabeng in the Bono East Region, Ghana
}

\author{
Thomas Yeboah $^{1 *}$, Charles Senior Afram ${ }^{2}$, Bernice Quampah ${ }^{3}$, Ahmed Kulega ${ }^{4}$ \\ Department of Hospitality and Tourism, Sunyani Technical University, Ghana ${ }^{1}$ \\ Department of Communication Studies, Sunyani Technical University, Ghana ${ }^{2,3,4}$ \\ tommyeboah@yahoo.com ${ }^{\prime *}$,framchasy@yahoo.com ${ }^{2}$, bernicequampah@yahoo.com ${ }^{3}$, \\ akulega@yahoo.com ${ }^{4}$
}

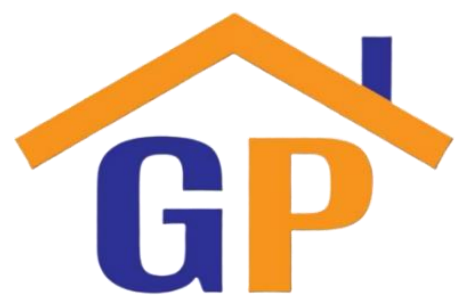

Abstract
Purpose: The purpose of this study was to evaluate adaptation
strategies developed by residents in order to minimize the risks
caused by the ecotourism project at Boabeng in the Bono East region
of Ghana.

Research methodology: Data collection instruments included schedules and interview guides. A sample of 404 heads of households was randomly selected for the administration of schedules, whilst 12 respondents each were purposively selected for focus group discussions and indepth interviews. Household data were analyzed using percentages, frequencies and mean responses.

\section{Article History}

Received on 6 May 2020

$1^{\text {st }}$ Revision on 17 May 2020

$2^{\text {nd }}$ Revision on 2 July 2020

$3^{\text {rd }}$ Revision on 23 July 2020

$4^{\text {th }}$ Revision on 1 August 2020

$5^{\text {th }}$ Revision on 14 August 2020

$6^{\text {th }}$ Revision on 19 August 2020

Accepted on 24 August 2020
Findings: Findings indicate that households adapted to ecotourism risks by patrolling and farming off the feeding range of the monkeys.

Limitations: Household heads and opinion leaders were made to assess the ecotourism project in terms of how they cope with it. These community leaders, some of whom were direct beneficiaries of the projects, may not give the right information and this may affect the results of the study. Respondents were however; assured of confidentiality of their responses so as to enable them give the right information on their adaptation to risks related to the ecotourism project in the community.

Contribution: This study recommends the intensification of livelihood diversification schemes in the study area.

Keywords: Destination, Limitations, Livelihood diversification, Local community, Local households, Monkey sanctuary, Vulnerable households

How to cite: Yeboah, T., Afram, C. S., Quampah, B., \& Kulega, A. (2019). Adaptation to risks related to ecotourism: development at Boabeng in the Bono East Region, Ghana. Journal of Sustainable Tourism and Entrepreneurship, 1(1), 105-121.

\section{Introduction}

Ecotourism sites around the world are usually natural resources that need very little capital to develop them. Ecotourism can bring about several benefits to a local community including reviving traditional culture and cultural pride of that particular area (Reimer \& Walter, 2013). This makes ecotourism development a sustainable means for making profit. In such situation, ecotourism brings some prospects for some modifications in local livelihoods (Tao \& Wall, 2009), especially where there are perceived livelihood dynamics due to ecotourism. In recent times, Ghana's ecotourism sector is doing well at maintaining a link between the local people, tourist and researchers. 
As a result, some of the local people have been able to receive profits because of the creation of poverty mitigation ecotourism related jobs for preservation of indigenous ecosystem and culture (Ghana Tourism Authority, 2010). Among the ecotourism sites in Ghana are the Mole National Park, Lake Bosumtwi, Nzulezu Stilt Village, Bobiri Forest and Butterfly Sanctuary, Bonwire Kente Weaving, Shai Hills, Larabanga Mosque and Boabeng-Fiema Monkey Sanctuary. Developing these attractions will enhance the development of local communities and to a large extent; help the tourism industry of the country. Since ecotourism to some extent, endangers rural economies, adaptation to risks related to ecotourism development is necessary for a successful interaction between households and ecotourism projects in destination areas.

Adaptation involves methods that lessen the adverse effects and furher enhance ecotourism's contribution to the development of local communities (Becken \& Hay, 2007). It is necessary to appreciate the way residents in the local communitties create their livelihoods. Livelihoods are capabilities, the assets and the activities required for a means of living (FAO, 2008). Vulnerable households found in destination communities involve themselves in various income generating endeavours to expand their source of income and reduce their risks. Turner, et al. (2003) see risks linked to ecotourism development as exposure to threats or dangers related to the growth of ecotourism in local communites. This current research was done at Boabeng in the Bono East region of Ghana.

Boabeng is about $22 \mathrm{~km}$ north of Nkoranza and has a total population of 1,186 made up of 569 males and 617 females. The average population growth rate in the community is about $3.1 \%$ and an economically active part of 56\% representing those aged 15years and above (Ghana Statistical Service, 2014). Boabeng has a traditional monkey sanctuary for Mona monkeys and Black and White Colobus monkeys. This eco-destination is special, since for a very long time, residents in the community have coped and adapted to the risks posed by monkeys in the community. These monkeys are giving befitting burial when they die and funerals are celebrated for them in the community.

The focus of this study is on adaptation and coping strategies used by many of the households at Boabeng to reduce the adverse impacts associated with the development of the Boabeng-Fiema Monkey Sanctuary (BFMS). The study also reveals the limits to local households' adaptive capacities. The broad adaptation strategies examined, therefore, sustain households' livelihoods that were found close to BFMS.

\section{Literature review}

\subsection{Political ecology theory}

The study examined the Political Ecology theory (Wallace, Cortner, Moote \& Burke, 1996), a field that analyses human-environmental interactions with specific emphasis on political issues that influence environmental change and natural resource degradation (Formo, 2010). To sustain the changes associated with the new livelihoods and land use practice of ecotourism, the adaptive management of the ecosystem highlighted in the political ecology concept (Wallace, Cortner, Moote \& Burke, 1996) was considered.

The adaptive management dimension therefore aimed at the required ecological conditions and the methods of attaining them from a social point of view on the assumption that the definition of an ecosystem and the criteria for a healthy ecosystem were basically value judgments (Norton, 1991). Adaptive management of ecosystem recognizes that managing human societies is part of maintaining healthy ecosystems which is also political since the local communities themselves need to determine the kind of benefits they will derive from their participation in ecosystem management. Therefore, ecotourism development as a land use and livelihood strategy subscribes to the concept of political ecology since it is essentially based on the inclusion and participation of the households in its governance.

\subsection{Ecotourism development}

In the opinion of (Ellis, 1998), livelihood diversification is a practice by which rural families create different groups of occupations and social support facilities in their toil for survival and in order to increase their standards of living. Ecotourism has become important because most local households have added it into their income generating activities as part of expanding their economic activities. 
Local residents have to cope with the distraction of daily life activities (Cernea, 2006), that occurs when livelihoods and practices are curtailed in the event to make room for tourism-related development (Schmidt-Soltau, 2003), and displacement (Coad et al., 2008), thus, forcing locals to resettle at places that are not fit for earning a living from the land (Agrawal \& Redford, 2009; Kuenzi \& McNeely, 2008). The study of forced resettlement has become something of a subject for discussion due to its increasing frequency as an appendage of development programmes. At Bui national park in Ghana for example, about eight communities had to be resettled to make way for the construction of the Bui hydro-electric power project.

Experiences have proved that a well adopted coping mechanism against ecotourism threats enables local people to conserve natural resources properly. A case in point is the Budongo wildlife sanctuary in northwestern Uganda, which according to Eshetu (2014) the surrounding communities were going into the reserve to collect food, building materials, fire wood, and materials for handicraft, and also use as agricultural land. As soon as some of the farmers were trained by the project to diversify their livelihoods into vegetable cultivation and beekeeping, their negative attitudes towards the project changed to positive and started to protect the forest destruction. Even women who had the chance to produce handicraft for sale and all those who were employed by the project as tour guides and caretakers of the reserve, started to involve in conservation practices (Langoya \& Long, 1997).

\subsection{Risks related to ecotourism development}

Ecotourism equip people with different skills and as a result, helps residents in rural communities to diversify their livelihood activities. There is further capital injection into the local economy from ecotourism as visitors spend money on indigenous food and souvenir shopping (Ogutu, 2002; Sunita, 2013). As a result, ecotourism may be used as a panacea for the diverging views between conservation and livelihood sustenance in the peripheries of protected areas (Balgah \& Nfor, 2017; Sama \& Molua, 2019).

Regrettably, several ecotourism projects seen as successful show insignificant change in existing resource-use practices for the local communities, bringing in threats to local livelihoods (Kiss, 2004). Many ecotourism development risks have been recorded in projects claiming to use ecotourism methods. Soil erosion, habitat alteration, air, noise and water pollution, litter, biodiversity loss, and the disruption of local flora and fauna are all recorded risks from ecotourism (Das \& Chatterjee, 2015; Novelli \& Gebhardt, 2009).

Another threat is that ecotourism can actually weaken local culture, even though it is this same culture that ecotourists long to see (Novelli \& Gebhardt, 2009). Surprisingly, by adding worth to indigenous cultures it becomes commodified, turning traditional events, rituals and even the local people themselves into a resource capable of being bought and sold (Barna, Epure \& Vasilescu, 2011; Leung et al., 2015). Intergovernmental Panel on Climate Change (IPCC, 2007) noted that vulnerability involves a combination of exposure and sensitivity to risk, and the inability to cope or adapt to ecotourism development risks in destination communities. Most often, the poor in especially developing countries are more vulnerable to risks related to ecotourism development.

Several studies have documented that wildlife and non-wildlife related risks factors have affected food security of rural households adjacent to wildlife management areas. Among these detrimental factors are: wildlife crop damage, livestock predation, floods, poor rainfall patterns, lack of agricultural extension services and poor use of improved agricultural input (Lyamuya et al., 2014; Mwakatobe et al., 2014). These risks, related to ecotourism development have reduced the livelihood options available to local households deprived of both crop production and income generation (Kaswamila, 2012; McCabe, et al., 2010; Nyahongo \& Røskaft, 2012).

\subsection{Adaptation to risks related to ecotourism development}

Adaptation is a process of deliberate change, either in anticipation of or in reaction to external processes of change (Nelson et al., 2007). Adaptation does not include just a decrease in vulnerability, but also taking advantage of positive change that offers opportunity for innovation and development (Intergovernmental Panel on Climate Change [IPCC], 2014). The concept of adaptation originated from population biology and evolutionary ecology, which relate to the genetic traits that permit living things to live and then procreate (Winterhalder, 1980). 
A coping range indicates an organism's immediate adaptive capability and adjustment that it can absorb without sustaining any major effects (Smit \& Pilifosova, 2003). Birkmann (2011) defined adaptive capacity as the medium or long-term ability of a system to adjust to external stimuli such as ecotourism development, climate change, etc., which may need institutional change. Local people's ability to adjust themselves to environmental changes can be assessed by means of their limits to environmental changes and coping ranges.

The abiliy to cope with risk related to ecotourism may lessen the impact; however, it does not warrant the capability to adjust oneself to environmental changes. Various researchers are of the view that the link between vulnerability and adaptive capacity is not all the time parallel to each order. This is because local households that are extremely vulnerable may also display extreme adaptive capacity (Gaillard, 2010; Handmer, 2003).

\subsection{Limits to adaptation to risks related ecotourism}

Adaptations aim to minimise potential negative impact on the ecosystem. However, factors that may account for the difficulty of local people to adapt to or cope with risks emanating from ecotourism development have been found to include poverty and lack of ability to cope with the menaces (Becken, 2013). IPCC (2007), opine that local residents' inability to adapt to environmental risks can be credited to lack of funds and structural constraints, inadequate access to capital such as markets, infrastructure and technology, environmental degradation and conflicts in destination communities.

Nevertheless, low capabilities can lead to low acclimatization to wildlife conservation and abortive risk reduction (Christoplos, 2008). Becken and Hay (2007) see barriers to adaptation to include lack of understanding of environmental effects, inadequate understanding of the likely adaptation choices and not taking into consideration the needs of future generations. Other barriers may include cultural constraints to certain adaptation responses, inadequate resources to execute the needed adaptation options, and not using collective approach in executing adaptation choices.

One approach to deal with risk related to ecotourism includes formation of partnership with management of the project and the key stakeholders to help bring down the constraints by putting together adaptive capacity (IPCC, 2007). The formation of this partnership will be necessary since traditional methods may not be enough to control risks stemming from wildlife conservation (Ford et al., 2006). Shakya (2009) suggestion is that expanding households' assets or encouraging different economic activities such as tourism to expand local livelihoods can support the capacity of indigenous people and therefore, destination communities should develop adaptation strategies or coping mechanism for survival. These methods lessen the harmful effects related to the biophysical and social conditions.

In response to both negative consequences and the influence of contextual factors, local households adopt strategies to improve their livelihood and food security (Agyeman, 2013; Barrett et al., 2001; McCabe, 2003; McCabe, et al., 2010; Ngailo, 2011; Nyahongo \& Røskaft, 2012; Paavola, 2008). These strategies are composed of both natural and non- natural resource based activities (Agyeman, 2013; Barrett et al., 2001; McCabe, 2003; Orindi et al., 2007; Orr \& Mwale, 2001; Paavola, 2008; Salafsky \& Wollenberg, 2000).

\section{Research methodology}

Methodologically, this study adopted qualitative research which allows vast life style experiences to be recorded and permits people in society to express their views as they wish (TuhiwaiSmith, 1999). Qualitative research is part of interpretivism, which is seen as a counter-reaction to positivism. Interpretivism draws on a constructivist ontology and subjectivist epistemology, which allows respondents to speak about their own lifestyles by gaining access to knowledge ignored in earlier period of more authoritative social research.

The study at BFMS shows that adaptation to ecotourism can be studied from both subjective and objective philosophical spectrums. In trying to use mixed methods approach for this study, the researchers adopted pragmatism which is a philosophical paradigm that takes into consideration a merger of both qualitative and quantitative approaches. The rationale behind the use of both quantitative and qualitative methods hinges on their suitability to the main principles of this study. 


\subsection{Target population}

This study targeted household heads or their reps in the Boabeng community whose age were 18 years or more. This group of people were selected to enable the researchers have a fair representative picture of the population in the community. Those aged 18 years and above were also targeted because people in the group were among the economically active population in the study area (Ghana Statistical Service, 2012). The target population for the qualitative aspect of the study comprised of the key informants such as farmers and workers of BFMS and other public sector workers like teachers in the Boabeng community. However, members of the Tourism management Committee (TMC) and the traditional council were engaged in focus group discussions.

\subsection{Sample size}

A list of household heads was gathered and used as a sample frame for the selection of the respondents. The unit of data collection was individual household heads in the community. The unit of interest was the household as this was typically considered the social group that make joint or coordinated decisions over resource allocation and income pooling (Allison \& Horemans, 2006).

The population and housing census list of Boabeng contained 232 houses from a total population of 1,186 as of 2010 (GSS, 2014). Since it was practically impossible to study all the people in the target population, a sample was chosen for the survey. Thus, to determine the sample size for the study, it was estimated that about $56 \%(0.56)$ of the economically active population at Boabeng, were aware of visitors' interest in the community's ecotourism project (GSS, 2014). This was because the community received a good number of tourists. The determination of the sample size using Fisher, et al.'s formula for calculating sample size is illustrated below;

$\mathrm{n}=\frac{\mathrm{z} 2 \mathrm{pq}}{\left(\mathrm{d}^{2}\right)}$

Where;

$\mathrm{n}=$ the desired sample size;

$\mathrm{z}=$ standard normal deviation set at 1.96 to $95 \%$ confidence level;

$\mathrm{p}=$ proportion of the target population that are aware of visitors' interest in the community's tourism project;

$\mathrm{q}=$ proportion of the target population that are not aware of visitors interest in the community's tourism project; and

$\mathrm{d}=$ degree of accuracy required normally set at 0.05 .

Let; $\mathrm{Z}=1.96, \mathrm{P}=0.56, \mathrm{q}=1.00-0.56=0.44$ and $\mathrm{d}=0.05$.

The sample size ' $n$ ' is therefore calculated as:

$$
\begin{aligned}
& \mathrm{n}=\frac{(1.96) 2 \times 0.56 \times 0.44}{(0.05)^{2}} \\
& \mathrm{n}=\frac{0.947}{0.0025} \\
& \mathrm{n}=379
\end{aligned}
$$

The value of ' $n$ ' indicated that at least 379 respondents had to be selected from Boabeng community to get a representative population. Nevertheless, about thirty-eight (38) respondents, which form $10 \%$ of the desired sample, were included to make room for non-response. In all, 417 members of the Boabeng community were to take part in the study.

\subsection{Sampling procedure}

The study used a simple random sampling procedure to select respondents. In this case, the researchers identified the number of households in each house and gave identification marks to each of the household heads. Household in this study refers to a person or group of persons related or unrelated who live together in the same house or compound, share the same housekeeping arrangement and are catered for as one unit (Ghana Statistical Service, 2012). When this study was conducted, Boabeng had more than 417 household heads. It was therefore necessary for random sampling to be carried out in each house. This was to ensure equal representation and also maintain equal chance of selecting each of the household head. It was also to make sure that newly established households were added to the 
survey. On the contrary, the approach ensured that those households that might have emerged or disappeared as a result of various reasons such as death or emigration were removed from the research.

In order for all household heads to have equal chance of inclusion in the study sample, each household was given a distinct code printed on a piece of paper and mixed in a sack and then each house code was drawn from the sack at random to select the households, which were about 417 household heads study population. The survey was then carried out in the various houses of the household heads who were residents in the community. If no knowledgeable household head was found in a particular household, it was avoided and replaced by the next with a suitable respondent. Respondents agreed for all interview responses to be recorded, and notes taken. It is perhaps necessary to state that a tour guide of the Boabeng-Fiema monkey sanctuary accompanied the researchers during the survey, but this did not slow down the selection process as he left as soon as he introduced the researchers to a particular household.

For the qualitative aspect of the study, 24 respondents were selected. 3 workers of the BFMS, 2 workers from the public sector and 7 farmers at Boabeng were purposively selected for the in-depth interview whilst 12 respondents (4 TMC members and 8 members of the Boabeng traditional council) were conveniently chosen for the focus group discussions. It was believed that the source of their livelihoods would make them privy to most of the risks associated with the development of the BFMS including their access to the forest and its products. All the FGDs were held at places prescribed by the discussants. In this case the discussion with the BFMS management team was held on Monday, 13 February, 2016 at the BFMS guesthouse whilst the FGDs with the Boabeng traditional council was held on Wednesday, $15^{\text {th }}$ February, 2016 at the chief's palace at Boabeng.

\subsection{Research instruments}

This study made use of the mixed methods research paradigm and as such, both quantitative and qualitative research instruments were used. Specifically, the main instruments used were interview schedule, in-depth interview guide and focus group discussion guides. These instruments were used because illiteracy levels were generally higher in rural areas (37.6\%) particularly the study area, than in urban (21.6\%) localities in Ghana (Ghana Statistical Service, 2012).

The interview schedule that was used in the survey was structured in English Language and administered by the researchers and four (4) field assistants in a local language (Asante Twi). This was because Asante Twi was the language mostly used by the people in the local area. The instrument consisted of a mix of open-ended and closed ended scale questions.

\subsection{Data processing and analyses}

Data from the interview schedule was examined for accuracy and completeness. The interview schedule was numbered serially, edited, coded and input into the Statistical Package and Service Solution (SPSS) software version 21 for further processing and analysis. Primarily, the study employed descriptive and inferential statistics. For descriptives analyses, bar charts, pie charts and percentages were used to explain the respondents' background information together with the scores of the various scale items.

Furthermore, inferential statistical tools were used to analyse the data. In this case, ranking of the livelihood activities were undertaken to determine limits to adaptation among the households in the community. This was done on the percentages of the overall data being studied. Data from the in-depth interview guide and focus group discussion guide were analysed with the thematic networks technique (Attride-Stirling, 2001) of qualitative data analysis.

\section{Results and discussions \\ Socio-Demographic Characteristics of the Respondents}

In terms of sex, results from the study showed that $43.1 \%$ of the respondents were males and $56.9 \%$ were females. Many of the respondents (48.3\%) were between 20 - 39 year aged groups, followed by 40 - 59 year aged group (38.9\%), with very few respondents above 60 years $(8.7 \%)$. With respect to educational level, over half $(59.2 \%)$ of the residents had only a basic education and $10.1 \%$ 
had completed secondary school and tertiary (4.7\%) education, whilst $26 \%$ did not have any formal education.

The majority (60.9\%) of respondents were married, $23.3 \%$ were single or never married with $15.8 \%$ ever married i.e. respondents who had married before but were either divorced or widowed. Over $57.0 \%$ of household respondents in the study area had average monthly income less than hundred Ghana cedis $(<\mathbb{\$ 1 0 0 )}$ and about $25.0 \%$ had average monthly incomes between $\mathbb{\$ 1 0 0}-\mathbb{\$} 199$. On the other hand, only about $6.4 \%$ of respondents had an average monthly income of over $\$ 499.00$.

About thirteen percent of respondents were traditionalists, with most of the respondents being Christians (86.4\%) and the remaining being Muslims (0.7\%). The dominant household size was more than 2 people in the community $(91.8 \%)$. About $5.0 \%$ of the respondents belonged to households of 2 members, with few respondents $(2.7 \%)$ staying as single-member household. The results of the study show that about $2.0 \%$ of respondents identified their jobs as tourism related (tour guides, wildlife officers, caretakers and cooks of the sanctuary) whilst about $98.0 \%$ of respondents identified their jobs as non-tourism related (including farmers, traders, artisans etc.).

\section{Methods employed by households to adapt to ecotourism risks}

Adaptation is a process of deliberate change, either in anticipation of or in reaction to external processes of change (Nelson et al., 2007). In a focus group discussion with management members of the BFMS, it came up that the monkeys in the sanctuary invaded nearby farms and raided houses in the community. Meanwhile, households received no compensation from the government or the sanctuary officials for destroyed food crops or household items. These ongoing damages to farms and households by especially, the Mona monkeys in the sanctuary were serious threats to household livelihoods and therefore the people needed to have a means to adapt to, or at least, cope with the risks they faced.

The study then, sought to find out from the respondents the methods they employed to deal with the risks from the ecotourism project. The result of the analysis as presented in Table 1 included the methods of adaptation such as: storing edible items in safe places $(9.9 \%)$; covering household items (28.1\%); patrolling both farms and homes to drive raided monkeys away from site $(51.0 \%)$; farming off the feeding range of the monkeys (8.9\%); and modifying methods of crop cultivation $(2.0 \%)$.

\section{Proper Storage}

In recent years, because of the increase in the monkey population, household and crop damage problems have become severe in a number of households bordering the sanctuary at Boabeng (Kipo per. Comm., 2016). Table 1 shows that about ten percent of the respondents cope with the risks emanating from the BFMS by storing edible items at safe places such as in cages and under lock and key in bedrooms which had also been ceiled to prevent the monkeys in the sanctuary from getting easy access to those edible items, whether these items were food or water. This seem to support Becken and Hay (2007) suggestion that adaptation is a dynamic process that influences how people adapt as well as how their needs are constantly changing.

In a focus group discussion with the tourism management committee in the study area, the $1^{\text {st }}$ participant lamented:

We have advised the local people not to leave their consumables and doors opened.

They are to always keep their valuable items at safe places to prevent the monkeys from destroying their valuables.

This implies that, proper storage of especially edible items by households emerged as one of the solutions to address some of the risks related to the ecotourism development that were evident at Boabeng. This adaptation method was considered relevant; particularly for households who were struggling to meet the challenges posed by the existence of the BFMS and was therefore expected to be heavily affected by the monkeys' invasion in their homes.

\section{Cover household items}

Methods to adapt to ecotourism risks can sometimes be planned, reactive or anticipatory, with the latter activities undertaken before adverse effects were observed. Table 1 shows that about twentyeight percent of respondents indicated that the Mona monkeys ate foodstuffs in households and raided almost everything in gardens thus adding cost to the households' livelihoods. As a result of this, among 
the proactive measures undertaken by households were to cover items in their homes to prevent monkeys from destroying those items. These were confirmed by various authors in the literature (Nelson et al., 2007; Smit \& Pilifosova, 2003). Nelson et al. (2007) for instance indicated that adaptation is a process of deliberate change, either in anticipation (proactive adaptation) of or in reaction (reactive adaptation) to external processes of change.

Some of the household respondents reported that they coped with the ecotourism risks by covering their valuable items in the house very well with sacks and heavy stones to prevent the monkeys from destroying those items (see Plates 1 \& 2).

\section{Modifying Methods of Crop Cultivation}

Adaptation involves not only reductions in vulnerability, but also taking advantage of positive change that provides opportunity for innovation and development (Moghal, 2015). Since the monkeys, most of the time attack mature crops such as maize, groundnut, plantain, banana and pineapples, two percent of household respondents were of the view that they coped with the monkey invasion by modifying their method of cultivation of crops on the farm in areas close to the sanctuary by harvesting their farm produce early enough or grow crops that were not eaten by the monkeys to avoid monkey invasion.

\section{Farming at distant places}

Some of the households reported that as a way to cope with the menace from the monkeys, they farmed at places which were far away from the forest where the monkeys stayed. When the schedules were administered to the household heads, about nine percent of the respondents confirmed that they farmed at distant places which they considered to be off the feeding range of the monkeys as shown in Table 1. This respondents admitted came as a great cost to them because, they either had to hire trucks to cart their farm produce to the house or had to rent farmlands at distant places.

\section{Patrols}

Table 1 also shows that a little more than half (51.0\%) of the respondents used patrols as adaptation strategy to drive the monkeys away from site or from monkey-invaded areas such as farms and homes. They explained that on seeing the monkeys, they shouted to drive them away, either from their homes or from their farms.

In an in-depth interview the $3^{\text {rd }}$ interviewee and a technical officer at Boabeng-Fiema monkey sanctuary had this to say;

The wildife officers came to this community to help the BFMS succeed because the traditional council's rules were not obliged by the local people so we came here to help protect the forest and to give technical advice. The animals are multiplying and farmers have to patrol their farms to keep the monkeys away. When there is not enough food in the forest, the monkeys are forced to visit home and eat food prepared by the local people. To save the situation, some of the animals can be re-located to different destinations. We have also requested for interventions such as beekeeping, soap making and gari processing which we need some financial help from benevolent organizations or NGOs.

This narrative indicates that financing of adaptation measures is important to consider, particularly for vulnerable households at Boabeng, where cost to household respondents were perhaps higher than existing income derived from the sanctuary.

\section{Collective Livelihood Adaptability Measures for Households' Survival}

In this study, collective livelihood adaptability measures among the local households were considered by exploring the capacity that enables the households to be resilient when confronted with ecotourism development related risks. Resilience is concerned with the magnitude of disturbances that can be absorbed or cushioned without undergoing fundamental changes (Berkes et al., 2003).

The study found that there were three basic collective adaptability measures adopted by local households to survive under the risks related to the ecotourism project in the community. These 
measures were communal work in the BFMS (21.8\%), communal work in the village $(65.6 \%)$ and collectively fighting bushfires (12.6\%) that occurred in the immediate environs as indicated in Figure 2.

\section{Communal work in the BFMS}

Resilience Alliance (2010) believe that, natural resource management issues are not just ecological or social issues, but also have multiple integrated factors including cultural, political, social, economic, ecological, technological, and other factors that work together as a team, that may be called social-ecological systems which is seen as a way of coping with stresses caused by ecological impacts. Figure 2 illustrates that about $22.0 \%$ of respondents as a way of coping with the ecotourism risks involved themselves in communal labour to work in the BFMS. This they did by constructing trails used by visitors in the sanctuary and also planted trees. Local households also helped remove litter from the forest to make the forest clean.

Some of the interviewees were of the view that there were also collective methods that seem to safeguard the environment. Respondents noted that traditionally, trees such as mahogany, odum, wawa and 'framo' in the protected area, were not demolished due to their medicinal and economic benefits.

These assertions also conformed to literature. Authors like Cline-Cole and O'Keefe (2006) and Saj, et al. (2006), noticed that local communities protect their natural environment since they depend on forest, grasslands and nearby bushes as sources of herbal medicines. Households also indicated that killing a monkey would bring bad omen to the offender and that protecting wildlife was important for ecotourism.

The tourism management committee members of the sanctuary argued that traditional beliefs were also behind the conservation of the BFMS. They explained that the monkey population had increased as a result of the whole community coming together to conserve the BFMS and enforcement of the local by-laws.

\section{Working in the community}

Figure 2 shows that the majority of respondents $(65.6 \%)$ participated in communal labour to help clean the village. Households revealed that they helped manage sanitation in the community by sweeping and weeding around the community as well as filling potholes on roads leading to Boabeng. In an in-depth interview, the $5^{\text {th }}$ interviewee who was also a leading member of the community said;

Boabeng is clean because I help organize communal labour to sweep and weed around the community. We remove dirt in the choked gutters and all rubbish from the community and burn them. When the community is clean, the visitors like it. Keeping the environment clean makes us, including visitors to this community healthy.

These assertions show that communal activity programs had helped improve the adaptation strategies used by people in the local community to lessening risks related to the health of the local people.

\section{Fighting bushfires}

Respondents were of the view that certain individuals in the community intentionally set fire to the vegetation set aside as protected area, which to the respondents, was dangerous since these fires, set arbitrarily, can destroy residents' food and income sources, wildlife habitats, tourism facilities and even human settlements. Results from Figure 2 showed that about $13.0 \%$ of respondents indicated that they used strategy such as fire volunteerism to protect the forest from bushfires. Also, it was found that community support was available for the local residents to manage fires. Respondents explained that Ghana National Fire Service stationed in the region, came to educate people in the community about the harm that fire can cause to the local livelihood activities. Because of the vegetative cover in the study area, if fire is not controlled, it could lead to food insecurity, loss of wildlife habitat and could also account for the dilapidation of BFMS.

Respondents indicated that around the forest, households had constructed green fire belt to prevent bushfire from destroying the sanctuary that habours monkeys which the local people see them as sacred animals. Moreover, residents were called upon anytime there was fire outbreak in the neighbourhood or someone needed help in putting off fire on his or her farm. Households regarded 
communal support as an essential resource accessible to them due to their inability to use fire service to contain bushfires.

\section{Limits to Adaptation at Boabeng}

Various studies (Blennow et al., 2012; Moser \& Erkstrom, 2010) have addressed and investigated adaptations while emphasising on its barriers. Similarly, most households in protected areas face a number of barriers or limitations in their attempt to adapt to ecotourism related risks because they have weak capacities. At Boabeng, barriers or limits to adaptation identified by the households were related to operational (37.9\%), structural (45.0\%) and cultural (17.1\%) as shown in Table 2 .

\section{Operational Limitations}

According to Christoplos (2008), vulnerable households will find it difficult to adjust themselves to wildlife conservation and will also find it difficult to reduce risk. About thirty-eight percent of household respondents asserted that limits to adaptation were operational and was ranked $2^{\text {nd }}$ as illustrated in Table 2 .

There are some issues in the local area that serve as hindrances during the implementation of participatory development approach, and this may be referred to as operational limitations to adaptation (Murray, 2004). The reason respondents gave to support this claim was that, there was limited understanding of the possible adaptation options (33.4\%) among households. The implication was that about thirty-three percent of the household respondents did not have or know any alternative means to stop the monkeys from attacking them both at their homes and on their farms.

Furthermore, about $5 \%$ of respondents were of the view that there was a lack of understanding of environmental effects among some households in the community. They reported that there were cases of bushfires purportedly started by some residents in some of the communities surrounding the BFMS. When there was bushfire too, some of the monkeys escape to the nearby communities causing damage to household livelihoods. There were also instances where some community members litter, smoke and defecate in the forest reserve, posing danger to living things in the forest and tourism in general.

\section{Structural Limitations}

When the limits to adaptation to risks from the BFMS were ranked, forty-five percent of household respondents identified leading limit to adaptation at Boabeng as structural as shown in Table 2. Structural limitations to adaptation at Boabeng relate to difficulties which can be linked to; local authorities managing the sanctuary, by-laws and businesses in the community (Murray, 2004; Steven \& Jennifer, 2002; Tosun, 2000). In this instance, respondents identified limited financial resources to implement the most desirable adaptation measures (39.6\%). Respondents indicated that in their view, some of the adaptation strategies which could have helped some of the households were to farm off the feeding range of the monkeys in the BFMS and additionally, to firmly secure their homes against monkey invasion by using wire mesh to fence corridors and even to support the ceilings of rooms. Yet, they had little money to secure their homes and further rent farmlands which were far away from the forest. Households indicated through interviews that even if they had their own farm lands far away from the forest, farming at such distant places served as huge cost to those of them who were peasant farmers since they needed to hire labour to work on those lands and what is more, needed money to board or hire vehicles (such as Kia trucks and tractors), to cart their farm produce like maize, cassava, plantain etc. to and from the house at huge transport cost.

In relation to the structural limitations was also, the lack of government support (5.4\%). Some households agreed that they failed to receive external support from especially the central government and the management authorities in the area. About five percent of the household respondents were of the opinion that the central government and the district assembly served as barriers to adaptation in the community. They explained that the central government through the district assembly and the management committee members had instituted many by-laws which prevented households from getting easy access to the forest designated as the monkey sanctuary. Meanwhile the government and 
the district assembly had failed to introduce livelihood interventions, failed to build health care facilities to cater for the health needs of the households and also failed to construct the poor roads leading to the community which could have attracted more investors and tourists to visit the community. With these, more employments would have been created for households to have livelihood options, since livelihood diversification is also a coping strategy (Ellis, 2000).

It was reported that households in the study area frequently lacked the means of improving their ability to adapt. Assets, which could have helped to increase households' ability to adapt to various changes influencing food security and general welfare, were reported to be lacking in the Boabeng community.

\section{Cultural Limitations}

Climate change studies focusing on social aspects of adaptation have classified limits to adaptation as ethics, knowledge or uncertainty, attitudes or perception of risks and culture (Adger et al., 2009). About seventeen percent of respondents indicated that limits to adaptation in the study area were cultural and therefore, cultural limitations were ranked $3^{\text {rd }}$ (Table 2). Cultural limitations to adaptation refer to the limited capacity of households to adjust to ecotourism development risks that affect their way of life.

Some of the respondents $(13.6 \%)$ recognized traditional beliefs as part of cultural barriers in the study area. Households were of the view that the monkeys were descendants of gods, and it was a taboo for households to treat them rudely. Households were therefore afraid when dealing with the monkeys, even in the instances where households found the monkeys destroying their livelihood activities.

In eco-destinations, there are many shocks and stresses that can destroy the natural resource base and subsequently affect household livelihood potentials over both the long and short term (Susannah, Chasca \& Stringer, 2010). Another cultural barrier identified by respondents was that, households appear to be divided in carrying out adaptation responses (3.5\%) as shown in Table 2 . Respondents explained that in some of the communities such as Boabeng and Fiema, a ban has been placed on the rearing and use of dogs for hunting. But in some of the allied communities including Bosunya, the district capital of the study area, the use of dogs in the communities was allowed and this is perhaps, one of the reasons why monkey-invasion in those communities, was minimal. These dogs, respondent believed could have even scared away the monkeys, especially those found in households adjacent to the sanctuary.

\section{Conclusion}

The findings of the research indicated that it was to protect the monkeys in the forest at Boabeng that informed management's decision to create green fire belt that prevented the local community from fire outbreak. This habit from the local authorities in charge of the sanctuary led to improved environmental management practices beyond the sanctuary, which lessened the community's exposure to fire damage and strong winds which could otherwise destroy several indigenous buildings. These adaptation methods adopted by the local people occurred in separate forms, complementing each other to decrease risks, enhance ecotourism benefits, and ensure households livelihood resilience.

There were three fundamental communal methods adopted by local households to survive under the risks related to the ecotourism project in the community. These were communal work in the forest, communal work in the village and fighting bushfires. Sustainable practices showed local residents' efforts made to help conservation of the protected area and households' livelihoods. Exercises of that nature were attributed to households' efforts in conserving indigenous trees and monkeys. Also, behavioural changes such as creation of green fire belt to reduce fire outbreak and to protect household livelihood assets and activities from bushfires, were indicated by respondents as part of different tools aimed at coping with ecotourism risks.

However, there were limits to adaptation in the study area identified by households as structural, cultural and operational barriers. Many of the households whose livelihood activities were located close to the sanctuary found it difficult to adapt to risks related to ecotourism development simply because they had limited capacity or had nothing to do in the face of monkey attacks and were also afraid of sanctions from the authorities. 
The findings of the research implied that many of the respondents adapted to ecotourism risk through the protection of farm crops and houses to reduce risks, such as monkey invasion, associated with the development of ecotourism in the study area. These adaptation strategies adopted by respondents reduced risks like home and crop raiding and at least, increased opportunities for improved households' livelihood outcomes.

It was as a result of social practices and organizations that restricted local people's access to resources undermining households' capacity to adapt to risks related to ecotourism development in the study area, whereby many of the households had little access to nearby lands for farming, building of houses, and other livelihood activities which hindered their ability to better adopt their preferred adaptation options.

\section{References}

Adger, W. N., Eakin, H., \& Winkel, A. (2009). Nested and teleconnected vulnerabilities to environmental change. Frontiers in Ecology and the Environment, 7(3), 150-157.

Agrawal, A. \& Redford, K. (2009). Place, conservation and displacement. Conservation and Society, $7(1), 56$.

Agyeman, Y.B. (2013). The role of local knowledge in sustaining ecotourism livelihood as an adaptation to climate change: $\mathrm{PhD}$ thesis. University of Waterloo.

Allison, E.H. \& Horemans, B. (2006). Putting the principles of the sustainable livelihoods approach into fisheries development policy and practice, arine Policy 30 (2006) 757-766.

Attride - Stirling, J. (2001). Thematic networks: an analytic tool for qualitative research, (London, Thousand Oaks, CA and New Delhi) vol. 1(3): 385-405, SAGE Publications.

Balgah S, Nfor F (2017). An Assessment of Ecotourism Potentials in Kupe Muanenguba Division, South West Region, Cameroon. International Journal of English, Literature Social Science 21:4.

Barna, C., Epure, M. \& Vasilescu, R. (2011). Ecotourism - Conservation of the Natural and Cultural Heritage. Review of Applied Socio-Economic Research, [online] 1(1), pp.87 - 95.

Barrett, C.B., Reardon, T. \& Webb, P. (2001). Non-farm income diversification and household livelihood strategies in rural Africa: concepts, dynamics, and policy implications. Food Policy, 26: 315-331.

Becken, S. (2013). A review of tourism and climate change as an evolving knowledge domain. Tourism Management Perspectives, 6, 53-62.

Becken, S., \& Hay, J. E. (2007). Tourism and climate change: Risk and opportunities. UK:Channel View Publication.

Berkes, F., Colding, J. \& Folke, C. (Eds.), (2003). Navigating social-ecological systems: Building resilience for complexity and change. New York, Cambridge University Press.

Birkmann, J. (2011). First and second order adaptation to natural hazards and extreme events in the context of climate change. Natural Hazards, 58(2), 811-840.

Blennow, et al., (2012). Climate change: Believing and seeing implies adapting. Plos one, 7(11), p.e 50182.

Cernea, M.M. (2006). Re-examining "displacement": A redefinition of concepts in development and conservation policies. Social change, 36 (1) 8-35.

Christoplos, I. (2008). Incentives and constraints to climate change adaption and disaster risk reduction: A local perspective. Sweden: The Commission on Climate Change and Development.

Cline-Cole, R. \& O'Keefe, P. (2006). Mainstreaming the environment in development? Review of African Political Economy 33(109): 377-390

Coad, L., Campbell, A., Miles, L. \& Humphries, K. (2008). The costs and benefits of protected areas for local livelihoods: A review of the current literature. Working Paper.

Das M, Chatterjee B (2015). Reviews in tourism Ecotourism: A panacea or a predicament? Tourism Management Perspectives 14:3-16.

Ellis, F. (1998). Household strategies and rural livelihood diversification. London, FrankCass \& Co. 35(1998) nr 1: S. 1-38. 
Ellis, F. (2000). Rural livelihoods and diversity in developing countries, Oxford: Oxford University Press

Eshetu, A.A. (2014). Development of community based ecotourism in Borena-Saynt National Park, North Central Ethiopia: Opportunities and challenges. Journal of hospitality and management tourism. Vol 5(1), pp 1-12.

FAO (2008). Climate change for fisheries and aquaculture. Technical background document form the expert consultation held on 7-9 April, 2008. Rome: United Nations Food and Agriculture Organization.

Ford, J. D., Smit, B. \& Wandel, J. (2006). Vulnerability to climate change in the arctic: A case study from arctic bay, Canada. Global Environmental Change, 16(2), 145-160.

Formo, R. K. (2010). Power and subjectivation: The political ecology of Tanzania's wildlife management areas. Master thesis, Norway, Norwegian University of Life Sciences (UMB).

Gaillard, J. C. (2010). Vulnerability, capacity and resilience: Perspectives for climate and development policy. Journal of International Development, 22, 218-232.

Ghana Statistical Service (2012). 2010 population and housing census: Summary report of final results. Accra: Ghana Statistical Service.

Ghana Statistical Service (GSS, 2014). 2010 population and housing census: District analytical report, Nkoranza North district. Accra: Ghana Statistical Service.

Ghana Tourism Authority (2010). Community-based ecotourism and poverty alleviation, final report, Accra 1-19:40-43.

Handmer, J. (2003). We are all vulnerable. Australian Journal of Emergency Management, 18(3-4), $55-60$.

IPCC (2007). IPCC fourth assessment report: Climate change 2007. Retrieve from: http://www.ipcc.ch/publications_and_data/ar4/wg1/en/tssts-4-1.html (accessed 31-08-16).

IPCC (2014). Climate change 2014. Impacts, adaptation and vulnerability. Glossary. IPCC 5th assessment report. Cambridge, Cambridge University Press, pp. 1-32.

Kaswamila, A. (2012). An analysis of the contribution of community wildlife management areas on livelihood in Tanzania. INTECH Open Access Publisher.

Kipo, Alex: Wildlife protection officer at BFMS, B/A region, Ghana (Personal communication of unpublished data, February, 2016).

Kiss A (2004). Is community-based ecotourism a good use of biodiversity conservation funds? Trends in Ecology and Evolution 19(6).

Kuenzi, C. \& McNeely, J. (2008). Nature-based tourism. In: Global Risk Governance: Concept and practice using the IRGC Framework (eds O. Renn and K.D. Walker).

International risk governance council book series, Springer, The Netherlands, pp. 155 - 178

Leung, Y., Spenceley, A., Hvenegaard, G. \& Buckley, R. (2015). Tourism and Visitor Management in Protected Areas: Guidelines for Sustainability. Best Practice Protected Area Guidelines Series. Gland, Switzerland: IUCN.

Langoya, C. D. \& Long, C. (1997). Local communities and ecotourism development in Budongo forest, Uganda. Retrieved from http//www.Odi.org on 4 / 07/ 15

Lyamuya, R., Masenga, E., Fyumagwa, R., \& Røskaft, E. (2014). Human-carnivore conflict over livestock in the eastern part of the Serengeti ecosystem, with a particular focus on the African wild dog Lycaon pictus. Oryx, 48(03), 378-384.

McCabe, J. T. (2003). Sustainability and livelihood diversification among the Maasai of northern Tanzania. Human Organization, 62(2), 100-111.

McCabe, J. T., Leslie, P. W., \& DeLuca, L. (2010). Adopting cultivation to remain pastoralists: The diversification of Maasai livelihoods in northern Tanzania. Human ecology, 38(3), 321-334.

Moghal, Z. (2015). A climate change vulnerability assessment of a tourism destination community (a case-study of Oistins, Barbados). PhD Thesis, Waterloo, Ontario, Canada, University of Waterloo.

Moser, S.C. \& Ekstrom, J.A. (2010). A framework to diagnose barriers to climate change adaptation. Proceedings of National Academy of Sciences. 107(51), pp 22026-22031.

Murray, C. (2004). Livelihoods research: Transcending boundaries of time and space. Journal of South African Studies 28(3): 489-509. 
Mwakatobe, A., Nyahongo, J., Ntalwila, J. \& Røskaft, E. (2014). The impact of crop raiding by wild animals in communities surrounding the Serengeti National Park, Tanzania. International Journal of Biodiversity and Conservation, 6(9), 637-646.

Nelson, F., Nshala, R. \& Rodgers, W. A. (2007). The evolution and reform of Tanzanian wildlife management. Conservation and Society 5:232-261.

Ngailo, J. (2011). Assessing the effects of eviction on household food security of livestock keepers from the Usangu wetlands in SW Tanzania. Livestock Research for Rural Development, 23(3), 2011.

Norton, B. (1991). The African elephant: Last days of Eden. Available at http://www.ntz.info/gen/n00419.html. Assessed on 10/7/2010.

Novelli, M., \& Gebhardt, K. (2009). Community-based tourism in Namibia: 'Reality show' or 'window dressing'. Eastbourne: University of Brighton.

Nyahongo, J., \& Røskaft, E. (2012). Assessment of livestock loss factors in the Western Serengeti,Tanzania: INTECH Open Access Publisher.

Ogutu ZA (2002). The Impact of Ecotourism on Livelihood and Natural Resource Management in Eselenkei, Amboseli Ecosystem, Kenya. Land Degradation and Development 13:251-256.

Orindi, V. A., Nyong, A., \& Herrero, M. (2007). Pastoral livelihood adaptation to drought and institutional interventions in Kenya. Human Development Report Office, Occasional Paper, 54.

Orr, A., \& Mwale, B. (2001). Adapting to adjustment: Smallholder livelihood strategies in Southern Malawi. World Development, 29(8), 1325-1343.

Paavola, J. (2008). Livelihoods, vulnerability and adaptation to climate change in Morogoro, Tanzania. Environmental Science and Policy, 11(7), 642-654.

Reimer J.K. \& Walter, P. (2013). How do you know it when you see it? Community based ecotourism in the Cardamom Mountains of southwestern Cambodia, Tourism Management, 34 (2013), pp. $122-132$

Resilience Alliance. (2010). From Science to practice: applying resilience thinking to regional planning in South-eastern Australia. Retrieved from https://www.resalliance.org/assessment-projects/4

Sama GL, Molua, EL (2019). Determinants of Ecotourism Trade in Cameroon. Natural Resources 10:202-217.

Saj, T. L., Sicotte, P. \& Paterson. J. D. (2006). The conflict between vervet monkeys and farmers at the forest edge in Entebbe, Uganda. African Journal of Ecology 39:195-199.

Salafsky, N., \& Wollenberg, E. (2000). Linking livelihoods and conservation: a conceptual framework and scale for assessing the integration of human needs and biodiversity. World development, 28(8), 1421-1438.

Schmidt-Soltau, K. (2003). Conservation-related resettlement in central Africa: Environmental and social risks. Development and Change, 34, 525-551. .

Shakya, M. R. (2009). Buddhist views on economic issues. In Buddhist approach to economic crisis. Phra Dharmakosajarn et al., eds. Bangkok: United Nations. Pp. 131 - 143.

Smit, B., \& Pilifosova, O. (2003). From adaptation to adaptive capacity and vulnerability reduction. In J. B. Smith, R. J. T. Klein \& S. Huq (Eds.), Climate change, adaptive capacity and development. River Edge, N.J.: Imperial College Press.

Steven, D., \& Jennifer, T. (2002). Challenges and barriers to community participation in policy development. From novascotia.ca/documents/policy/challenges\%20and\%20barriers.pdf

Susannah, M. S. Chasca, T. \& Stringer, L. C. (2010). Resilience or vulnerability livelihoods? Assessing livelihood dynamics and trajectories in Rural Botswana. Retrieved from http://www.ecology society.org (12/6/2015)

Tao, T. C. H., \& Wall, G. (2009). Tourism as a sustainable livelihood strategy. Tourism Management, 30(1), 90-98.

Tosun, C. (2000). Limits to community participation in the tourism development process in developing countries.Tourism Management, 21(6), 613-633. 
Tuhiwai-Smith, L., (1999). Decolonizing Methodologies: Research and Indigenous

Peoples. Dunedin: University of Otago Press.

Turner, B. L., Kasperson, R. E., Matson, P.A., McCarthy, J., Corell, R.W, Christensen, L. \& Eckley, N. (2003). A framework for vulnerability analysis in sustainability science. Proceedings of the National Academy of Sciences 100 (14): 8074-8079

Wallace, M. G., Cortner, H. J., Moote, M. A., Burke, S. (1996). Moving towards ecosystem management: Examining a change in philosophy for resource management. Retrieved from http://jpe.library.arizona.edu (26/07/2016)

Winterhalder, B. (1980). Environmental analysis in human evolution and adaptation research. Human Ecology, 8, 135-170.

\section{APPENDICES}

Table 1

Methods Employed to Adapt to Ecotourism Development Related Risks

\begin{tabular}{lll}
\hline Methods & $\mathrm{N}$ & $\%$ \\
\hline Store edible items in safe places & 30 & 9.9 \\
Cover household items & 85 & 28.1 \\
Patrol to drive raided monkeys away from site & 154 & 51.0 \\
$\begin{array}{l}\text { Farm at distant places which are off the feeding range } \\
\text { of monkeys }\end{array}$ & 27 & 8.9 \\
$\begin{array}{l}\text { Modify methods of crop cultivation } \\
\text { Total }\end{array}$ & 6 & 2.0 \\
\hline
\end{tabular}

$\mathrm{N}=302 ; \mathrm{N}<404$, because of non-response

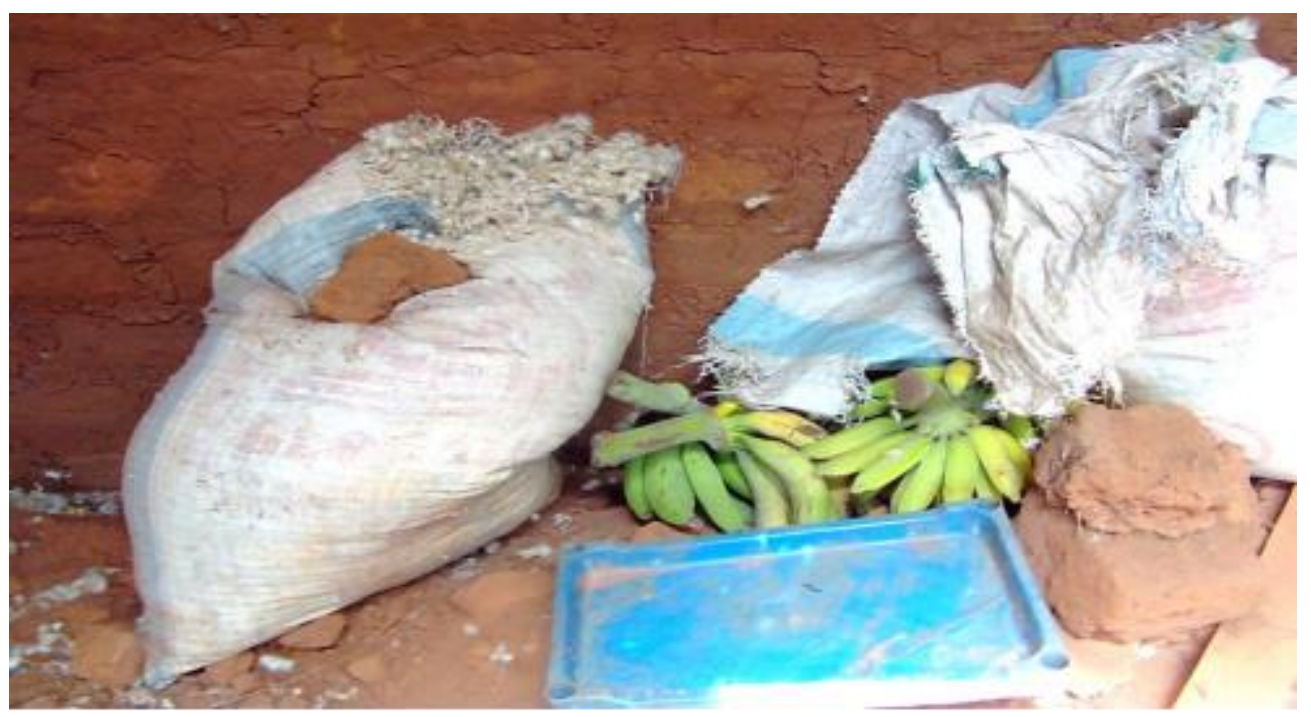

Plate 1: Foodstuffs to Be Covered to Avoid Monkey-Damage 


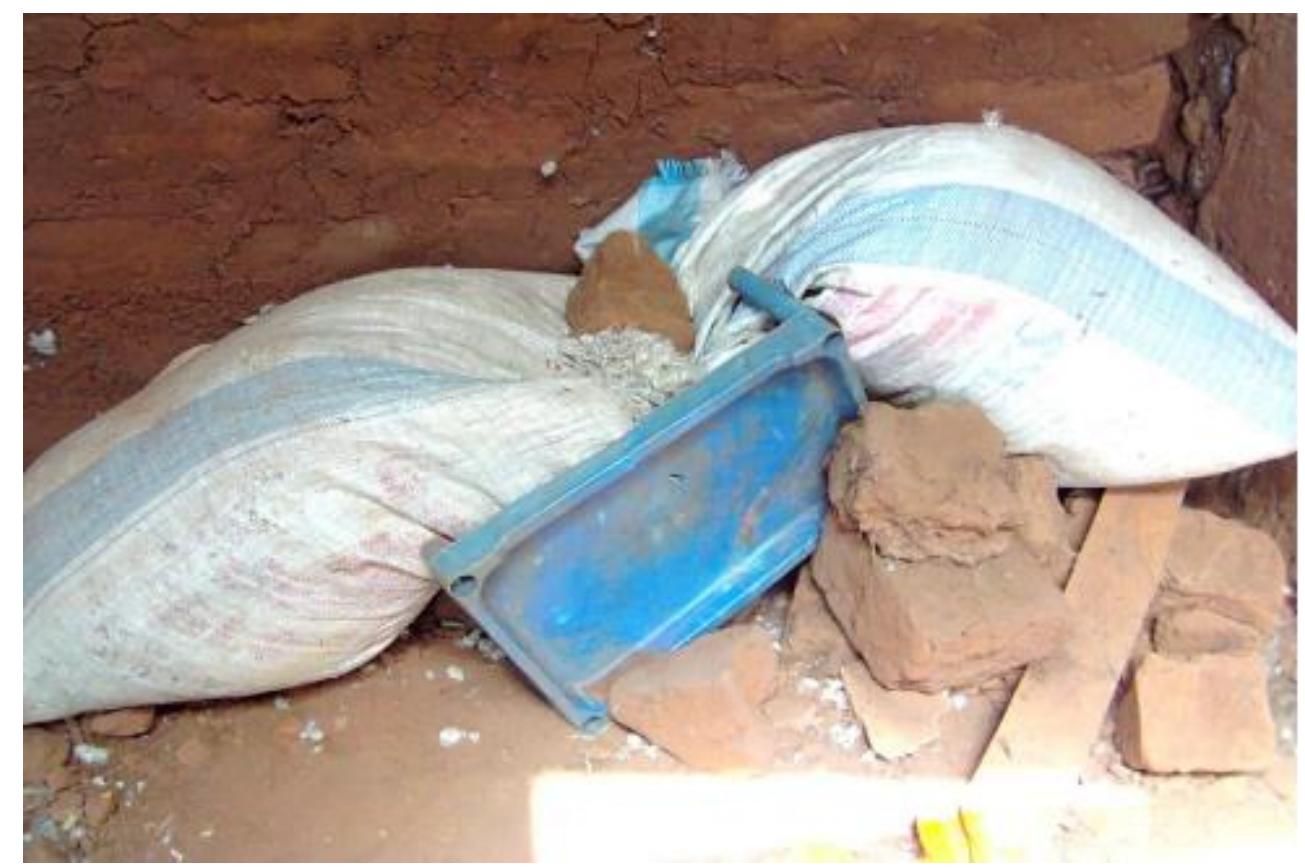

Plate 2: Foodstuffs Covered to Prevent Damage by Monkeys

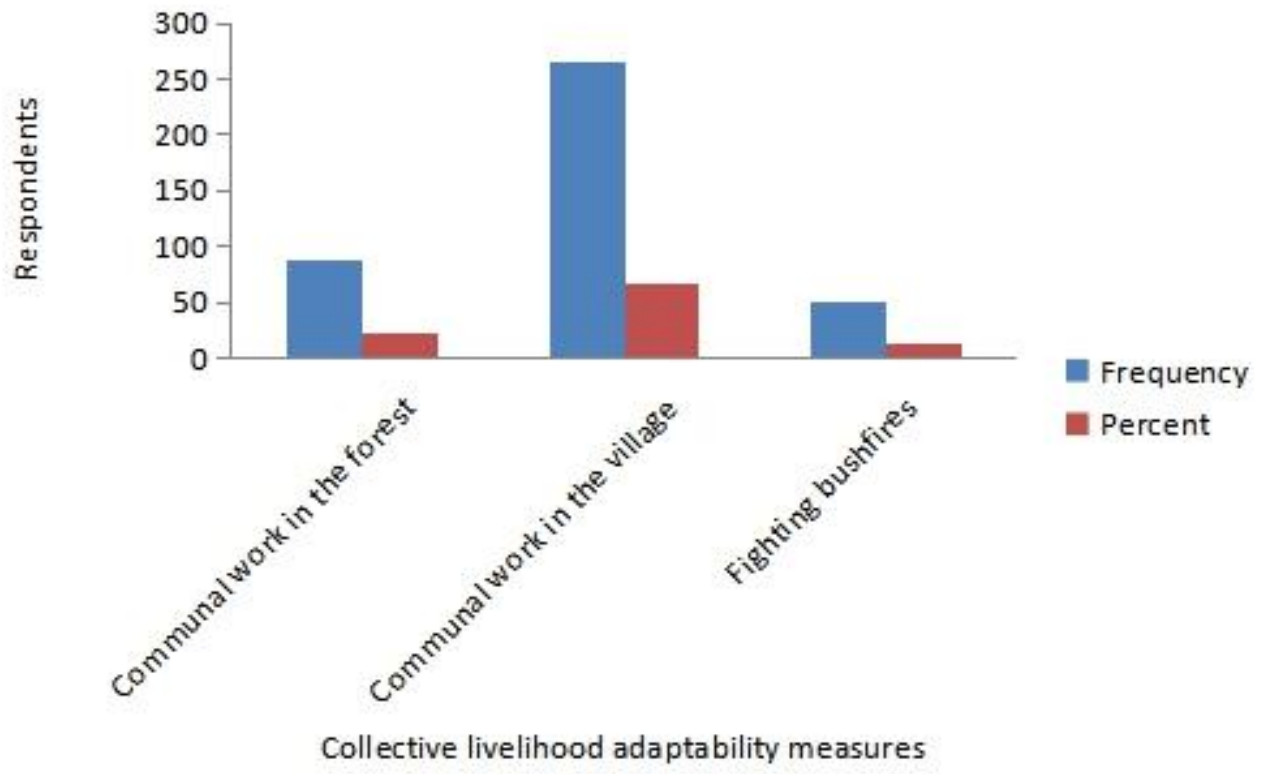

Figure 2: Bar Graph Showing Collective Livelihood Adaptability Measures for Households' Survival

Table 2

Limits to Adaptation to Risks from Boabeng-Fiema Monkey Sanctuary

\begin{tabular}{|c|c|c|c|c|}
\hline $\begin{array}{l}\text { General } \\
\text { limitations }\end{array}$ & Specific limitations & $\%$ & Total & Ranking \\
\hline \multirow[t]{2}{*}{ Operational } & $\begin{array}{l}\text { Limited understanding of adaptation } \\
\text { options }\end{array}$ & 33.4 & 37.9 & 2 \\
\hline & $\begin{array}{l}\text { Lack of understanding of } \\
\text { environmental effects }\end{array}$ & 4.5 & & \\
\hline
\end{tabular}




\begin{tabular}{|c|c|c|c|c|}
\hline Structural & $\begin{array}{l}\text { Inadequate funds to put into practice } \\
\text { the needed adaptation methods } \\
\text { Lack of government support to } \\
\text { implement adaptation strategies }\end{array}$ & 39.6 & 45.0 & 1 \\
\hline \multirow[t]{2}{*}{ Cultural } & $\begin{array}{l}\text { Traditional beliefs } \\
\text { Lack of understanding by local } \\
\text { people to implement adaptation } \\
\text { methods }\end{array}$ & $\begin{array}{l}13.6 \\
3.5\end{array}$ & 17.1 & 3 \\
\hline & $\begin{array}{l}\text { Total } \\
\mathrm{N}\end{array}$ & $\begin{array}{l}100.0 \\
404\end{array}$ & & \\
\hline
\end{tabular}

